\title{
Tissue engineering of heart valves by recellularization of glutaraldehyde-fixed porcine valves using bone marrow-derived cells
}

\author{
Sang-Soo $\mathrm{Kim}^{1,4}$, Sang-Hyun $\mathrm{Lim}^{6}$, \\ Seung Woo $\mathrm{Cho}^{5}$, So-Jung Gwak ${ }^{3}$, \\ Yoo-Sun Hong ${ }^{7}$, Byung Chul Chang ${ }^{7}$, \\ Moon Hyang Park', Kang Won Song ${ }^{2}$, \\ Cha Yong Choi ${ }^{4,6}$ and Byung-Soo Kim ${ }^{1,8}$ \\ ${ }^{1}$ Department of Bioengineering \\ ${ }^{2}$ Department of Pathology \\ ${ }^{3}$ Department of Chemical Engineering \\ Hanyang University \\ Seoul 133-791, Korea \\ ${ }^{4}$ Interdisciplinary Program for \\ Biochemical Engineering and Biotechnology \\ ${ }^{5}$ School of Chemical and Biological Engineering \\ Seoul National University \\ Seoul 151-742, Korea \\ ${ }^{6}$ Department of Thoracic and Cardiovascular Surgery \\ Ajou University School of Medicine \\ Suwon 443-749, Korea \\ ${ }^{7}$ Division of Cardiovascular Surgery \\ Yonsei Cardiovascular Center \\ College of Medicine Yonsei University \\ Seoul 120-752, Korea \\ ${ }^{8}$ Corresponding author: Tel, 82-2-2220-0491; \\ Fax, 82-2-2291-0838; E-mail, bskim@hanyang.ac.kr
}

Accepted 24 May 2006

Abbreviations: BMC, bone marrow-derived cell; DAB, 3,3'-diaminobenzidine tetrahydrochloride; $\mathrm{EB}$, ethidium bromide; $\mathrm{EC}$, endothelial cell; eNOS, endothelial nitric oxide synthase; FDA, fluorescein diacetate; GA, glutaraldehyde; H\&E, hematoxylin and eosin; KDR, kinase-insert domain-containing receptor; M199, Medium 199; MF, myofibroblast; MHC, myosin heavy chain; MSC, mesenchymal stem cell; MTT, 3-(4,5-dimethylthiazol-2-yl)-2,5-diphenyltetrazolium bromide; PCNA, proliferating cell nuclear antigen; SEM, scanning electron microscopy; SM, smooth muscle; TCP, tissue culture plastics

\footnotetext{
Abstract

To increase the biocompatibility and durability of glutaraldehyde (GA)-fixed valves, a biological coating with viable endothelial cells (ECs) has been proposed. However, stable EC layers have not been formed successfully on GA-fixed valves due to their inability to repopulate. In this study, to improve
}

cellular adhesion and proliferation, the GA-fixed prostheses were detoxified by treatment with citric acid to remove free aldehyde groups. Canine bone marrow mononuclear cells (MNCs) were differen tiated into EC-like cells and myofibroblast-like cells in vitro. Detoxified prostheses were seeded and recellularized with differentiated bone marrowderived cells (BMCs) for seven days. Untreated GA-fixed prostheses were used as controls. Cell attachment, proliferation, metabolic activity, and viability were investigated and cell-seeded leaflets were histologically analyzed. On detoxified GA-fixed prostheses, BMC seeding resulted in uninhibited cell proliferation after seven days. In contrast, on untreated GA-fixed prostheses, cell attachment was poor and no viable cells were observed. Positive staining for smooth muscle $\alpha$-actin, CD31, and proliferating cell nuclear antigen was observed on the luminal side of the detoxified valve leaflets, indicating differentiation and proliferation of the seeded BMCs. These results demonstrate that the treatment of GA-fixed valves with citric acid established a surface more suitable for cellular attachment and proliferation. Engineering heart valves by seeding detoxified GA-fixed biological valve prostheses with BMCs may increase biocompatibility and durability of the prostheses. This method could be utilized as a new approach for the restoration of heart valve structure and function in the treatment of end-stage heart valve disease.

Keywords: bone marrow cells; endothelial cells; heart valve prosthesis; tissue engineering

\section{Introduction}

Replacement of heart valves with mechanical or biological prostheses is currently a common treatment for end-stage valvular diseases (Lupinetti et al., 1997). These heart valve prostheses substantially reduce the mortality of patients, but the prostheses have severe limitations. Mechanical valve prostheses are associated with a high incidence of thromboembolism due to their poor blood compatibility, and require long-term use of anti-clotting medication (Lupinetti et al., 1997). Biological tissue 
valve prostheses, such as glutaraldehyde (GA)-fixed xenografts and cryopreserved homografts, suffer from limited durability and dysfunctions due to progressive tissue degeneration, and therefore may require successive surgery to replace the prostheses (Yacoub et al., 1995). The major disadvantage of GA-fixed tissue valve prostheses is the degeneration of grafts, with subsequent calcification and tissue failure (Sodian et al., 2000). This may result from an inability of host cells to repopulate the valve due to the GA-fixation process (Yacoub et al., 1995).

Various strategies have been proposed to improve the performance of GA-fixed heart valve bioprostheses (Moritz et al., 1990; Zilla et al., 1997; Weissenstein et al., 2000; Trantina-Yates et al., 2001; Gulbins et al., 2003). One method involves the use of a biological coating of viable endothelial cells (ECs) to increase the biocompatibility and durability of GA-fixed valves. By covering the surface of the valve prostheses with autologous ECs, valve degeneration and thromboembolic events may be reduced. However, stable EC layers have not been formed successfully on GA-fixed valves due to their inability to be repopulated (Fischlein et al., 1992; Hoffmann et al., 1992; Bengtsson et al., 1993; Fischlein and Fasol, 1996). Methods that have previously been tested to improve cellular adhesion on GA-fixed prostheses include pretreatment of the prostheses with amino acid solutions (Fischlein et al., 1994) or citric acid solutions (Gulbins et al., 2003), and precoating the valves with fibronectin or growth factors (Fischlein et al., 1994).

The purpose of this study was to develop a detoxifying treatment method for GA-fixed prostheses that would enable seeded bone marrow-derived cells (BMCs) to cover the luminal surface of the prostheses. Canine BMCs were used as a cell source instead of vascular-derived ECs to overcome the problems of limited availability of intact vasculature and the invasiveness during cell harvest, which results in morbidity at the donor sites (Kadner et al., 2002). Seeding of BMCs on detoxified and untreated GA-fixed bioprosthetic tissues was investigated in vitro. GA-fixed porcine pulmonary valves were treated with a detoxifying agent to establish a more suitable surface for BMC attachment and proliferation by removing cytotoxic free aldehydes. The detoxified prostheses were seeded and recellularized in vitro with bone marrow-derived myofibroblast (MF)-like cells and EC-like cells for seven days. The attachment, proliferation, metabolic activity, and viability of the seeded cells were investigated and cell-seeded leaflets were histologically analyzed.

\section{Materials and Methods}

\section{Detoxification of glutaraldehyde-fixed porcine valves}

Commercially available GA-fixed porcine mitral valve prostheses (model $=342 \mathrm{R}$, size $=33 \mathrm{~mm}$, Hancock Heart Valve, Medtronic Inc., Houston, TX) were rinsed three times with sterile distilled water and transferred to Medium 199 (M199, Gibco BRL, Gaithersburg, MD). Valves were incubated for $24 \mathrm{~h}$ at $4^{\circ} \mathrm{C}$ and then treated with $10 \%(\mathrm{w} / \mathrm{v})$ citric acid solution (Sigma, St. Louis, MO) for 5 min to neutralize the cytotoxic effect of free aldehydes (Gulbins et al., 2003). Residual reagents were removed by repeated washes in distilled water until neutral $\mathrm{pH}$ was achieved.

\section{Culture of BMCs}

Bone marrow (30 $\mathrm{ml}$ from each dog) was aspirated from the humeri of anesthetized mongrel dogs $(20-25 \mathrm{~kg})$ and immediately mixed with heparin (100 unit heparin $/ \mathrm{ml}$ bone marrow). The mixture was centrifuged on a Ficoll-Paque (Amersham Bioscience, Arlington Heights, IL) density gradient for 20 min at $1,500 \mathrm{rpm}$. Mononuclear cells were isolated from the buffy coat layer and washed three times in PBS (Sigma). The mononuclear cell fraction containing smooth muscle (SM) $\alpha$-actin-positive cells (MF-like cells) was cultured in M199 (Gibco BRL) containing $10 \%(\mathrm{v} / \mathrm{v})$ FBS (Gibco BRL) and 1\% (v/v) penicillin and streptomycin (Gibco BRL). The mononuclear cell fraction containing CD31-positive cells (EC-like cells) was cultured in EGM-2 (Clonetics, San Diego, $\mathrm{CA})$.

\section{Characterization of BMCs}

Cultured BMCs were stained immunochemically using antibodies against SM $\alpha$-actin (Clone 1A4, 1:100 dilution) (Dako, Carpinteria, CA) and CD31 (Clone JC/70A, 1:20 dilution) (Dako). Cultured cells were fixed with a $4 \%(\mathrm{v} / \mathrm{v})$ paraformaldehyde solution for $30 \mathrm{~min}$ and permeabilized with $0.1 \%(\mathrm{v} / \mathrm{v})$ Triton X-100 (Sigma) for 10 min. After treatment with $3 \%(\mathrm{v} / \mathrm{v})$ hydrogen peroxide (Sigma), cells were incubated at room temperature with primary antibodies for two hours and with biotinylated antimouse IgG secondary antibody (Vector Laboratory, Burlingame, CA) for $30 \mathrm{~min}$. Signals were developed using a streptavidin biotin universal detection system (UltraTech HRP, Immunotech, Marseille, France) and a 3,3'-diaminobenzidine tetrahydrochloride (DAB) substrate solution (Vector Laboratory).

\section{Semi-quantitative reverse transcription (RT)-PCR}

Total RNA was isolated from cultured EC-like cells 
and MF-like cells using RNeasy Mini kit (Qiagen, Hilden, Germany) according to the manufacturer's protocol. cDNA was synthesized with $5 \mu \mathrm{g}$ of pure total RNA using SuperScript ${ }^{\mathrm{TM}}$ II reverse transcriptase (Invitrogen Life Technologies, Carlsbad, CA) (Choi et al., 2004). cDNA was amplified with a thermal cycler (GeneAmp PCR System 2700, Applied Biosystems, Foster City, CA) using the primers in Table 1. PCR was performed for 30 cycles of denaturing $\left(94^{\circ} \mathrm{C}, 30 \mathrm{~s}\right)$, annealing $\left(60^{\circ} \mathrm{C}, 30 \mathrm{~s}\right)$, and extension $\left(72^{\circ} \mathrm{C}, 45 \mathrm{~s}\right)$ with a final extension at $72^{\circ} \mathrm{C}$ for $7 \mathrm{~min}$. PCR products were visualized by electrophoresis on $2 \%(\mathrm{w} / \mathrm{v})$ agarose gels containing 0.5 $\mu \mathrm{g} / \mathrm{ml}$ ethidium bromide and analyzed with a gel documentation system (Gel Doc 1000, Bio-Rad Laboratories, Hercules, CA).

\section{Cell seeding and in vitro maintenance}

Valves were sequentially seeded with MF-like cells (SM $\alpha$-actin-positive cells) followed by EC-like cells (CD31-positive cells). SM $\alpha$-actin-positive cells were uniformly seeded onto the valve leaflets at a cell density of $8.0 \times 10^{6}$ cells per prosthesis. Two hours later, CD31-positive cells were uniformly seeded onto the valve leaflets at a cell density of $2.0 \times 10^{6}$ cells per prosthesis. Seeded valve prostheses were maintained in vitro in cell culture flasks (Bellco Glass Inc., Vineland, NJ) containing Medium 199 supplemented with $2 \%(\mathrm{v} / \mathrm{v}) \mathrm{FBS}$, human vascular endothelial growth factor (10 ng/ml; PeproTech, Rocky Hill, $\mathrm{NJ})$, and human basic fibroblast growth factor $(2 \mathrm{ng} / \mathrm{ml}$; PeproTech) for one week (Figure 1). Samples were taken one, four and seven days after cell seeding.

Table 1. Oligonucleotide primers used for RT-PCR and predicted product sizes.

\begin{tabular}{llcc}
\hline \multicolumn{1}{c}{ Targets } & \multicolumn{1}{c}{ Sequences } & $\begin{array}{c}\text { Product } \\
\text { sizes (bp) }\end{array}$ & References \\
\hline \multirow{2}{*}{ eNOS } & F: 5'-TCA ACC AGT ACT ACA GCT CC-3' & 251 & Kalra et al., 2003 \\
& R: 5'-GTG GTT GCA GAT GTA GGT GA-3' \\
KDR & F: 5'-TTC CTG ACC TTG GAG CAT CT-3' & \multirow{2}{*}{ Murata et al., 2000 } \\
& R: 5'-AGT CCA GCA TGG TCT GGT AC-3' & & Ishida et al., 2000 \\
SM $\alpha$-actin & F: 5'-GCC AAC CGG GAG AAA ATG AC-3' & 743 & Ishida et al., 2000 \\
& R: 5'-TCC TGT TTG CTG ATC CAC AT-3' & & Ishida et al., 2000 \\
\hline
\end{tabular}
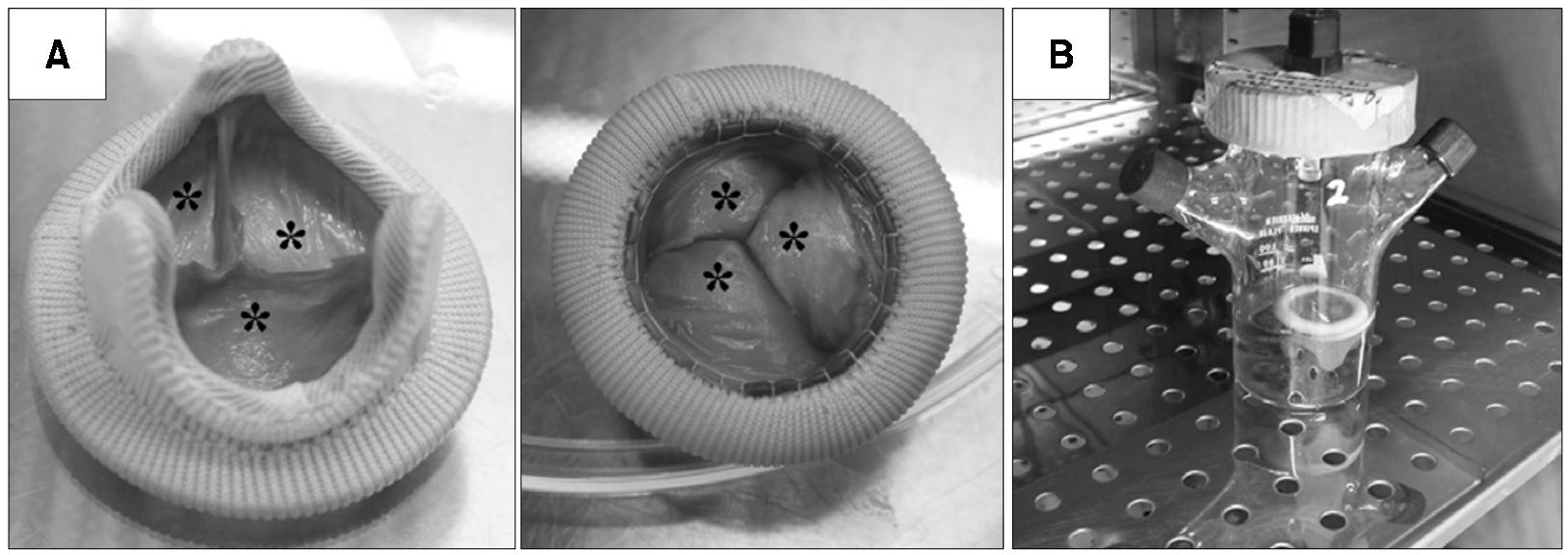

Figure 1. BMC seeding on detoxified GA-fixed heart valve prostheses. (A) Gross view of cell-seeded heart valve prostheses. Tri-leaflets (asterisks) are observed. (B) Cell-seeded prostheses were maintained in vitro in cell culture flasks for seven days. 


\section{Scanning electron microscopy}

Scanning electron microscopy (SEM) of the valve leaflets was performed before and after cell seeding. Specimens were fixed, dehydrated and dried. Dried specimens were mounted on aluminum supports and coated with platinum using a Sputter Coater (Cressington Scientific Instruments Inc., Cranberry, PA).
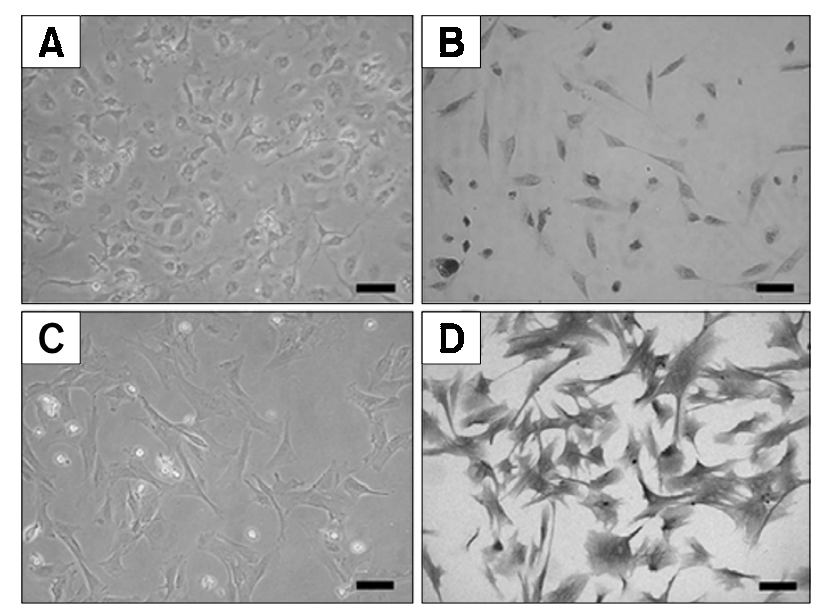

$\mathbf{F}$
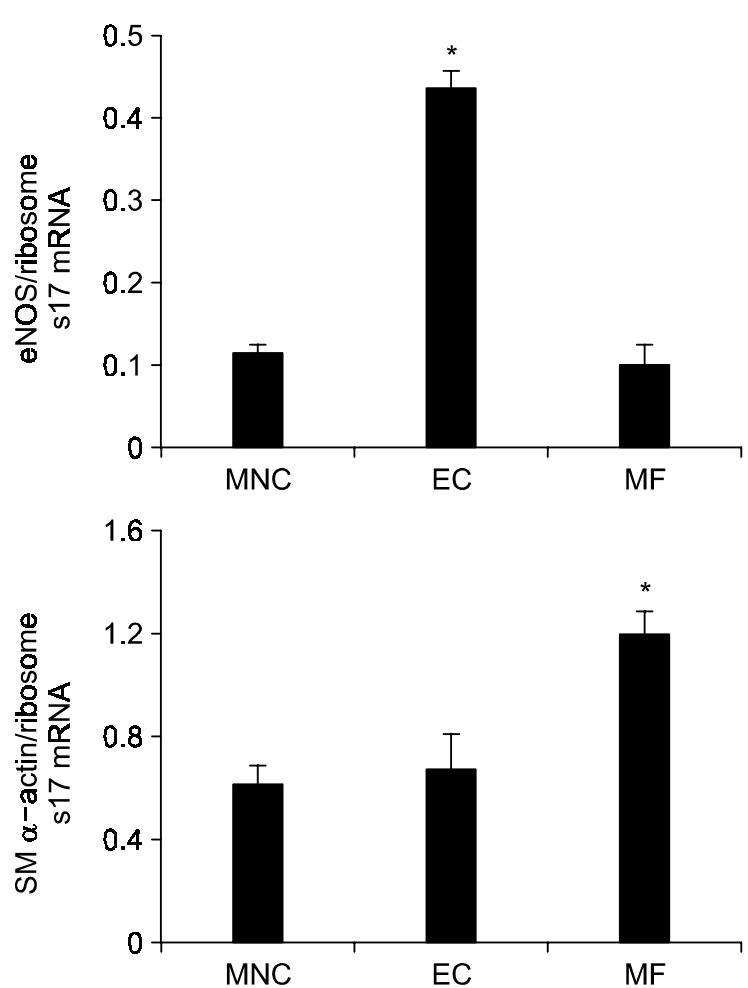

SEM (JEOL, Tokyo, Japan) was performed at $5 \mathrm{kV}$.

\section{DNA quantification}

To measure cell growth on the prostheses, the number of cells was determined by quantitative DNA assays performed in triplicate. DNA was isolated
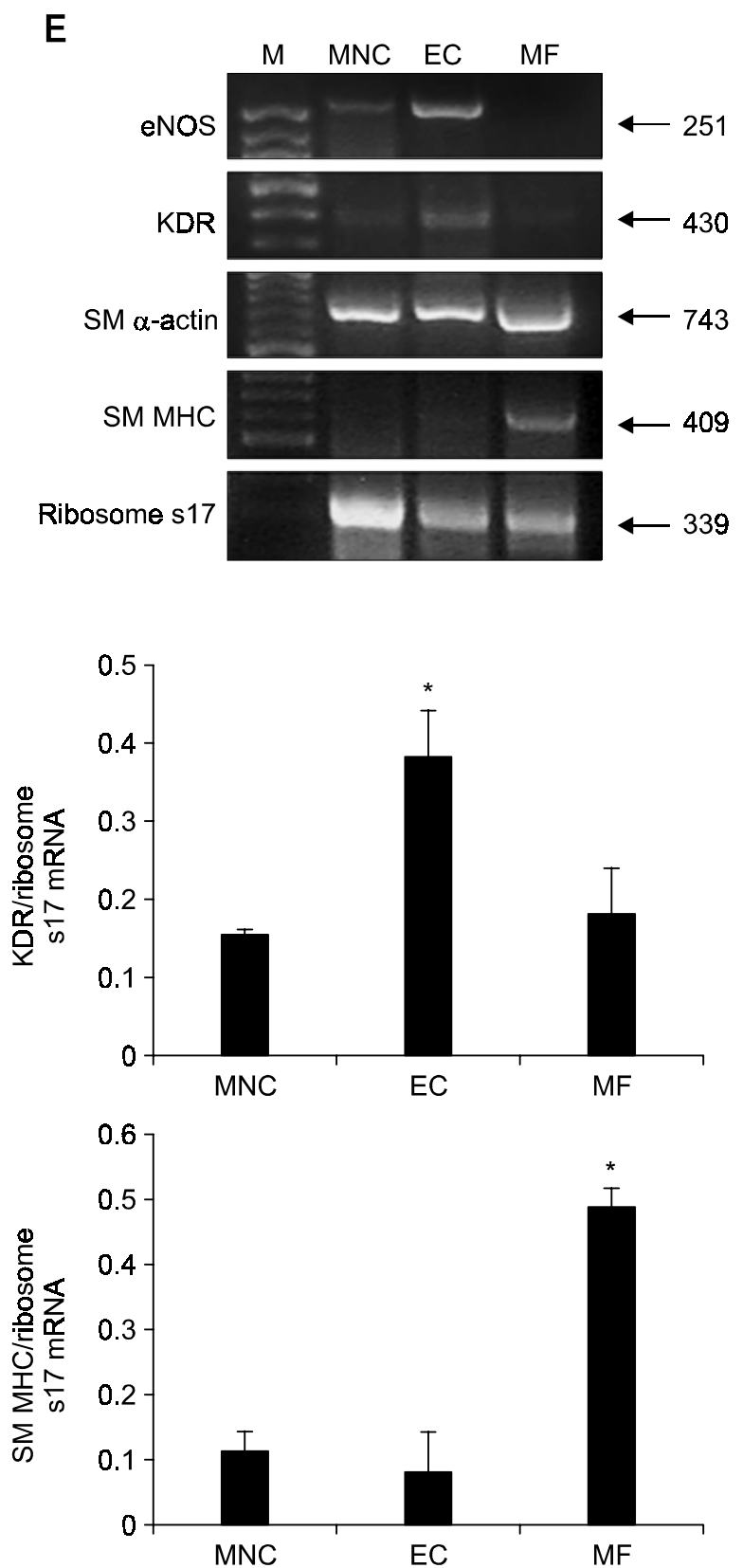

Figure 2. Characterization of cultured canine BMCs. BMCs cultured in EC culture condition showed the cobblestone morphology typical of ECs (A) and stained positively for CD31, a specific marker of ECs (B). BMCs cultured in MF cell culture condition had morphology similar to that of MFs (C) and stained positively for SM $\alpha$-actin, a specific marker of MF (D). (E) The mRNA expression of markers of ECs (eNOS and KDR) and markers of MFs (SM $\alpha$-actin and SM MHC) in BMCs cultured in EC-like and MF-like cell culture conditions. ( $F$ ) Expression of each gene mRNA was normalized with house keeping Ribosomal s17 mRNA. The scale bars indicate $10 \mu \mathrm{m} .{ }^{*} P<0.05$ compared with the other groups. 

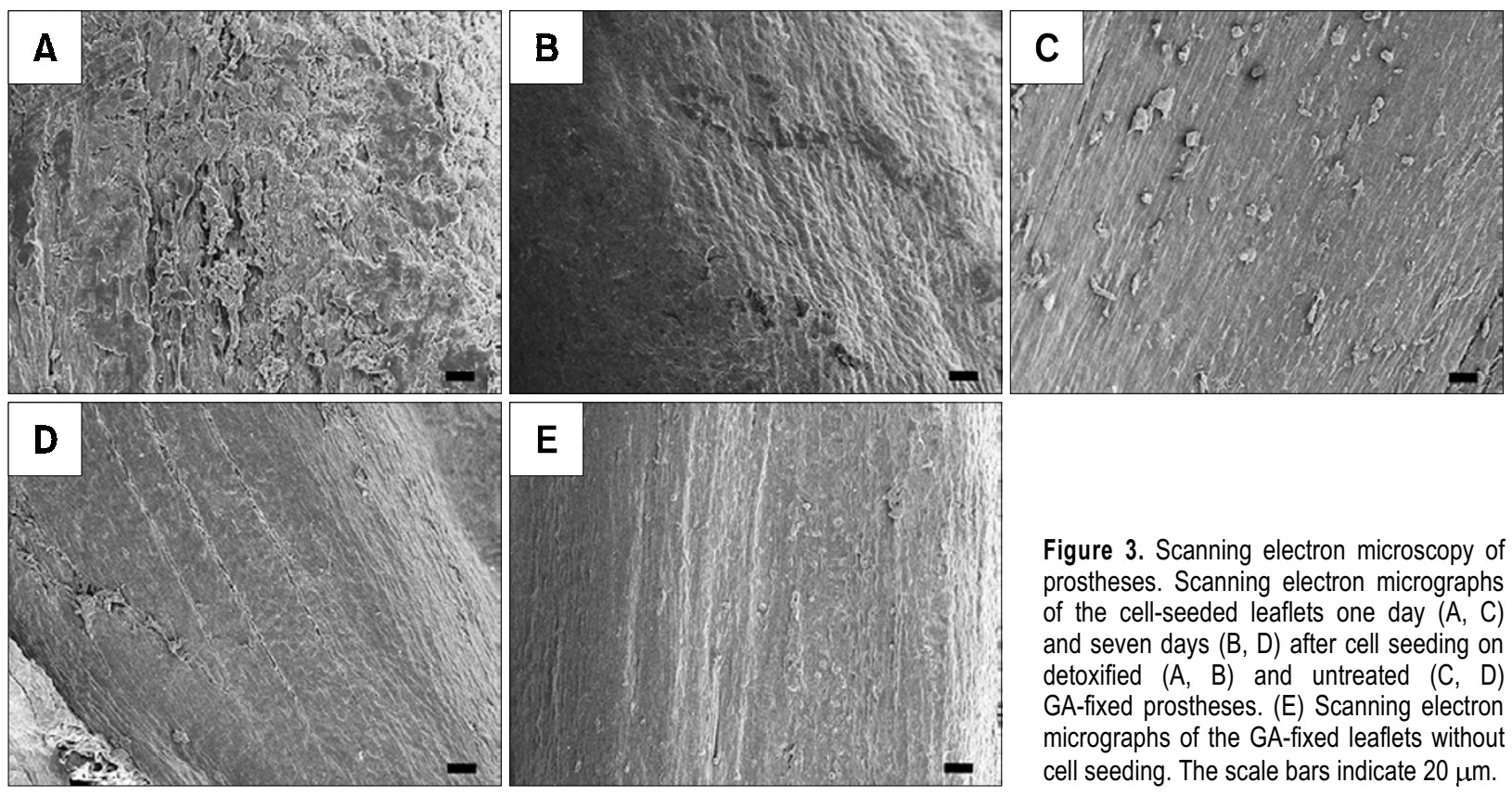

Figure 3. Scanning electron microscopy of prostheses. Scanning electron micrographs of the cell-seeded leaflets one day $(A, C)$ and seven days $(B, D)$ after cell seeding on detoxified $(A, B)$ and untreated $(C, D)$ GA-fixed prostheses. (E) Scanning electron micrographs of the GA-fixed leaflets without cell seeding. The scale bars indicate $20 \mu \mathrm{m}$.

using a Wizard Genomic DNA Purification kit (Promega, Madison, WI) according to the manufacturer's protocol. DNA content was measured with an ultraviolet absorbance spectrophotometer (UV-160A spectrophotometer, Shimadzu, Kyoto, Japan) at 260 $\mathrm{nm}$. Cell numbers were calculated using a DNA standard curve for identical cells.

\section{MTT assay}

Mitochondrial metabolic activity of cells cultured on tissue culture plastics (TCP) and on GA-fixed prostheses was measured in triplicate using the 3-(4,5dimethylthiazol-2-yl)-2,5-diphenyl-tetrazolium bromide) (MTT) assay (Liu et al., 2005). MTT stock solution (1 $\mathrm{mg} / \mathrm{ml}$; Sigma) was added to cultured cells and incubated at $37^{\circ} \mathrm{C}$ for $4 \mathrm{~h}$. Following removal of the medium, formazan precipitates were solubilized by the addition of $1 \mathrm{ml} 0.1 \mathrm{~N} \mathrm{HCl}$ solution containing $10 \%(\mathrm{w} / \mathrm{v})$ sodium dodecyl sulfate and $45 \%(w / v)$ dimethylformamide. Absorbance at 540 $\mathrm{nm}$ was measured using a microplate reader (Multiskan Spectrum, Thermo Electron Co., Vantaa, Finland).

\section{Cell viability assay}

The viability of cells seeded on the GA-fixed prostheses was measured by double staining using fluorescein diacetate (FDA, green fluorescence; Sigma) and ethidium bromide (EB, red fluorescence; Sigma) (Ryu et al., 2004). The staining solution was prepared by combining $10 \mathrm{ml}$ of FDA solution (5

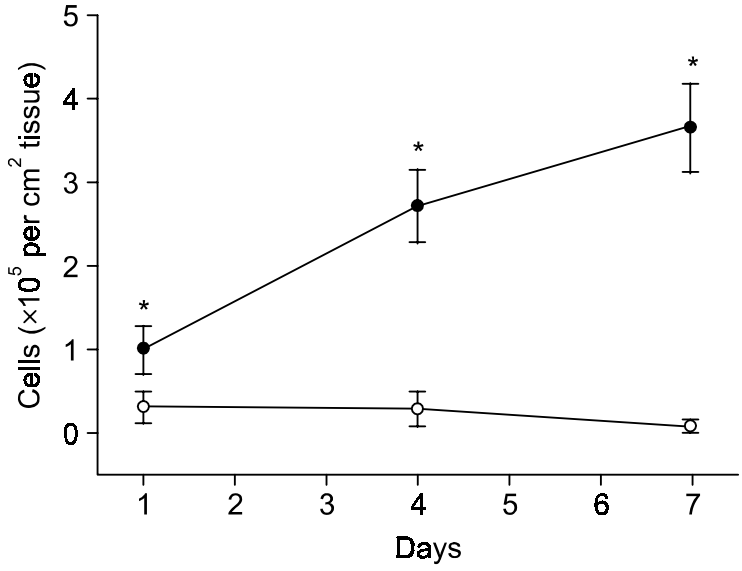

Figure 4. BMC proliferation on detoxified (solid circles) and untreated (open circles) GA-fixed prostheses. BMCs cultured on untreated prostheses showed decreased proliferation, while BMCs cultured on detoxified prostheses showed uninhibited proliferation. ${ }^{*} P<0.05$ compared with untreated group.

$\mathrm{mg} / \mathrm{ml}$ in acetone) and $5 \mathrm{ml}$ of EB solution $(10 \mu \mathrm{g} / \mathrm{ml}$ in PBS). Samples were incubated in FDA/EB solution for $5 \mathrm{~min}$ at $37^{\circ} \mathrm{C}$, washed twice in PBS, and observed under confocal microscopy (Fluoview BX50, Olympus, Tokyo, Japan).

\section{Histological and immunohistochemical analyses}

For histological analyses, specimens were fixed in $10 \%(\mathrm{v} / \mathrm{v})$ buffered formaldehyde and dehydrated with an ascending series of graded ethanol. Spe- 
FDA

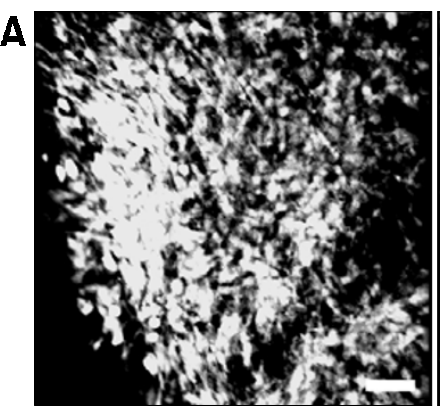

B
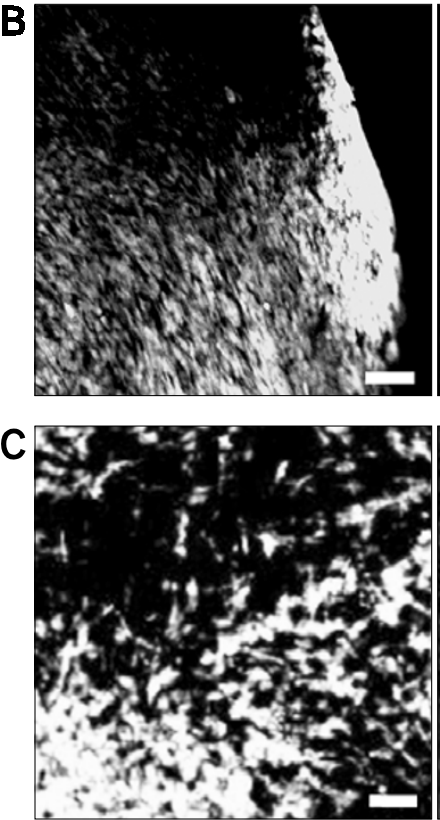

D

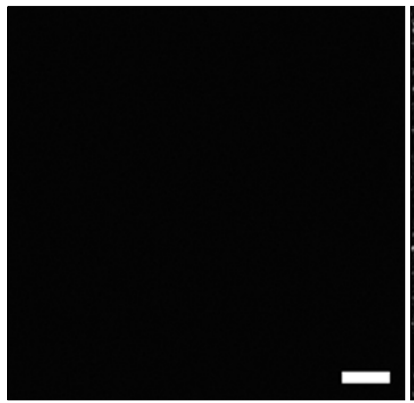

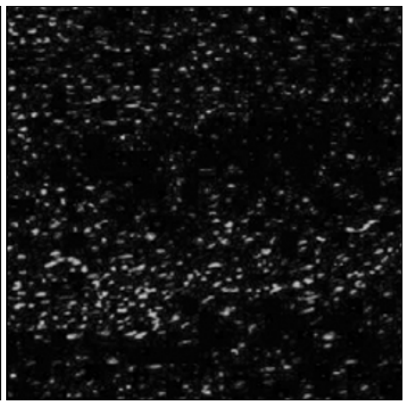

EB
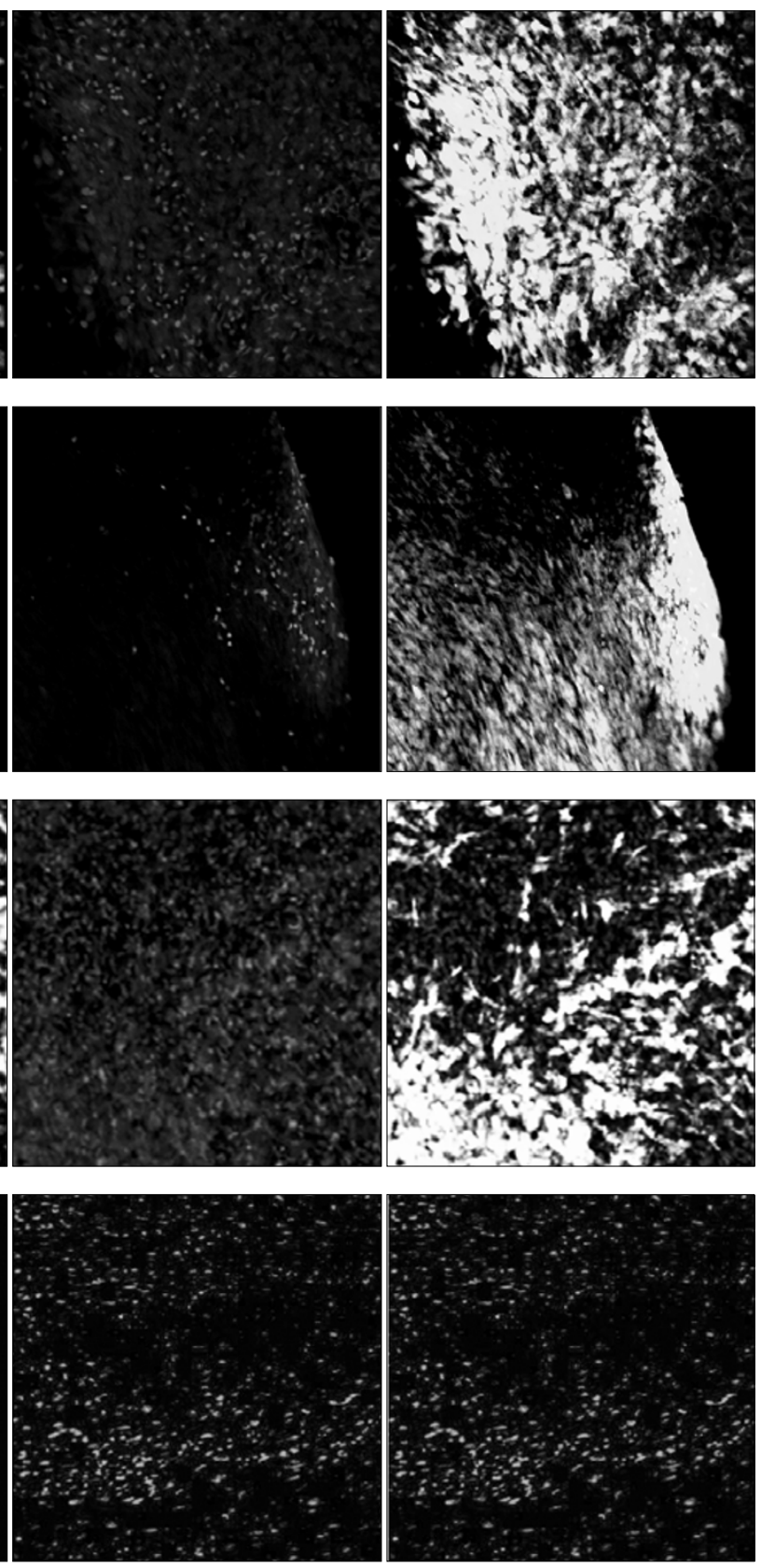

Merge
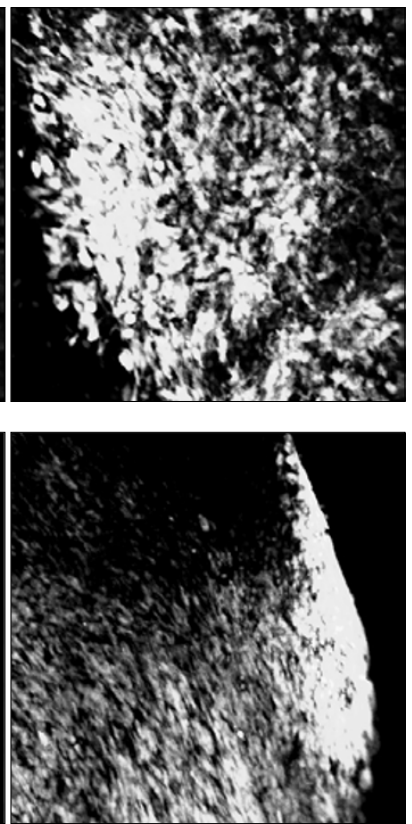

Figure 5. Confocal microscopy of cell-seeded leaflets of detoxified $(A, B)$ and untreated $(C, D)$ $G A$-fixed prostheses stained with FDA and EB one day $(A, C)$ and seven days $(B, D)$ after cell seeding. Figure in the far left column indicate viable cells (green signals and figures in the middle column indicate dead cells (red signals), respectively. The scale bars indicate $20 \mu \mathrm{m}$. All photographs were taken at the same magnification. cimens were embedded in paraffin, sectioned at 4 $\mu \mathrm{m}$, and processed for hematoxylin and eosin (H\&E) staining. For immunohistochemical analyses, $4 \mu \mathrm{m}$ thick sections were stained using antibodies against CD31, SM $\alpha$-actin, and PCNA (Clone PC10, 1:200 dilution; Dako). Sections were deparaffinized and incubated at room temperature with primary antibodies for two hours and biotinylated anti-mouse IgG secondary antibodies for $30 \mathrm{~min}$. Staining signals were developed using the streptavidin biotin universal detection system and DAB substrate solution.

\section{Results}

\section{Differentiation and characterization of BMCs}

Cultured canine BMCs were able to differentiate into EC-like cells and MF-like cells in vitro. BMCs grown in the EC culture condition showed the characteristic cobblestone morphology of ECs (Figure 2A) and 

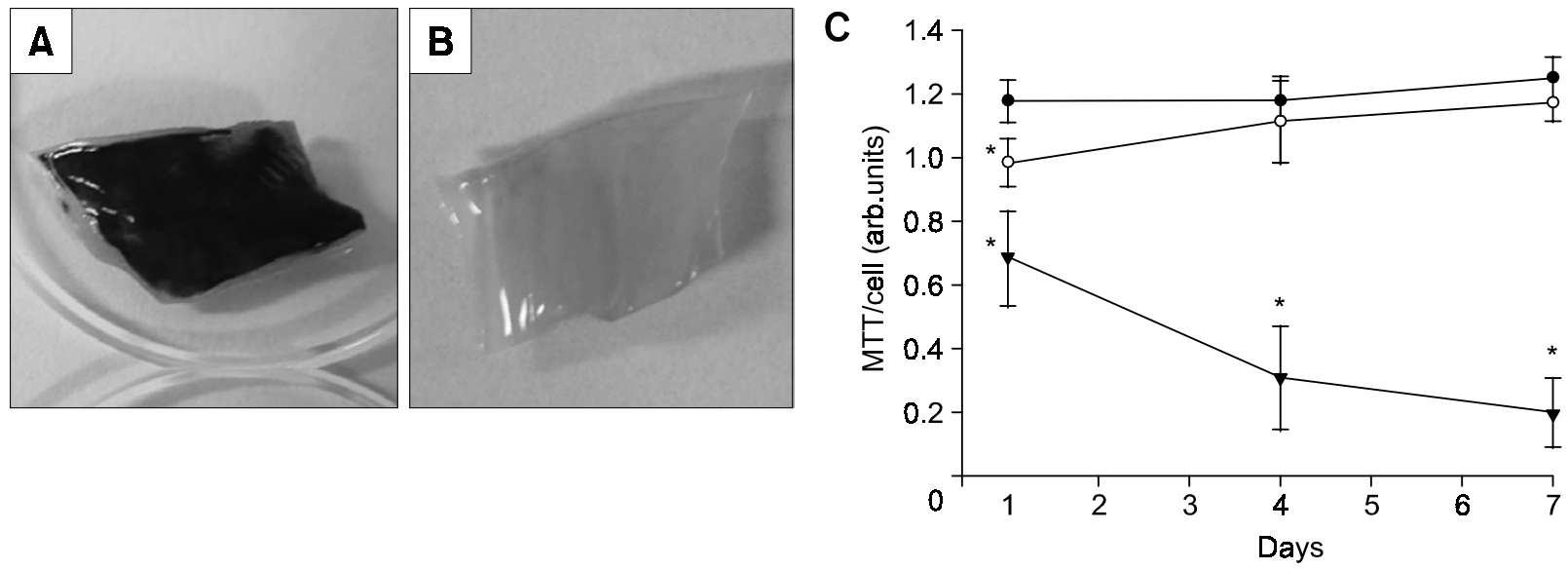

Figure 6. MTT staining of BMCs seeded on detoxified (A) and untreated (B) GA-fixed prostheses seven days after cell seeding. Formation of formazan precipitates was observed on detoxified prostheses (A), but not on untreated prostheses (B). (C) Metabolic activity of BMCs cultured on TCP (solid circles), detoxified (open circles), and untreated (solid inverted triangles) GA-fixed prostheses. ${ }^{*} P<0.05$ compared with TCP.

stained positively for CD31, a marker of ECs (Figure 2B). BMCs grown in the MF culture condition had morphology similar to MFs (Figure $2 \mathrm{C}$ ) and expressed SM $\alpha$-actin, a marker of MFs (Figure 2D). The mRNA markers of ECs, endothelial nitric oxide synthase (eNOS) and kinase-insert domain-containing receptor (KDR), were expressed at a higher extent in the BMCs cultured in the EC-like cell culture condition than freshly isolated bone marrow MNCs and cells cultured in the MF-like cell culture condition. The mRNA markers of MFs, SM $\alpha$-actin and SM myosin heavy chain (MHC), were expressed at a higher extent in BMCs cultured in the MF-like cell culture condition than freshly isolated bone marrow MNCs and cells cultured in the EC-like cell culture condition (Figure 2E and F).

\section{Seeding on GA-fixed prostheses}

GA-fixed valve prostheses, with or without detoxifying treatment, were seeded with EC-like cells and MF-like cells differentiated from bone marrow MNCs, and maintained in vitro for one week. Pretreatment of GA-fixed prostheses with $10 \%(\mathrm{w} / \mathrm{v})$ citric acid improved the efficiency of BMC seeding. SEM analysis showed that BMC seeding on detoxified GA-fixed valves resulted in even cell attachment one day after seeding (Figure $3 \mathrm{~A}$ ) and formation of a confluent layer of cells over the surface of the valve leaflets after one week (Figure 3B). In contrast, BMC seeding on untreated GA-fixed valves resulted in scattered BMCs on the surface one day after seeding (Figure 3C) and disappearance of these cells after seven days (Figure 3D).

\section{Cell proliferation on GA-fixed prostheses}

Detoxified GA-fixed prostheses allowed adhesion and proliferation of seeded BMCs over a culture period of seven days. The initial cell seeding density of $3.0 \times 10^{5}$ cells $/ \mathrm{cm}^{2}$ resulted in $1.1 \times 10^{5} \mathrm{cells} / \mathrm{cm}^{2}$ remaining attached to the detoxified GA-fixed valve after one day in culture, an adhesion percentage of $36.7 \%$ (Figure 4). For the untreated GA-fixed valve, the cell adhesion efficiency was $17.2 \%$. Seeded BMCs also grew more rapidly in the detoxified GA-fixed valve than in the untreated GA-fixed valve. After seven days in culture, the average cell density of the detoxified GA-fixed valve was $3.7 \times 10^{5}$ cells $/ \mathrm{cm}^{2}$, while that of the untreated GA-fixed valve was $0.1 \times 10^{5} \mathrm{cells} / \mathrm{cm}^{2}$, corresponding to a $236 \%$ increase and $90.9 \%$ decrease in cell density compared to the initial cell adhesion densities for the detoxified and untreated GA-fixed valves, respectively (Figure 4).

\section{Cell viability on GA-fixed prostheses}

Viability of BMCs seeded on GA-fixed prostheses was examined by fluorescent microscopy with differential staining for viable and nonviable cells: FDA stains the cytoplasm of viable cells green and EB stains the nuclei of nonviable cells orange-red. Confluent viable cells were present on the surface of detoxified GA-fixed prostheses one day after seeding (Figure 5A). Most of the cells showed FDApositive staining (green fluorescence) seven days after cell seeding, indicating that they remained viable during the in vitro culture periods (Figure 5B). In contrast, cell viability decreased over time on untreated GA-fixed prostheses. One day after seeding on untreated valves, more than half of the cells 

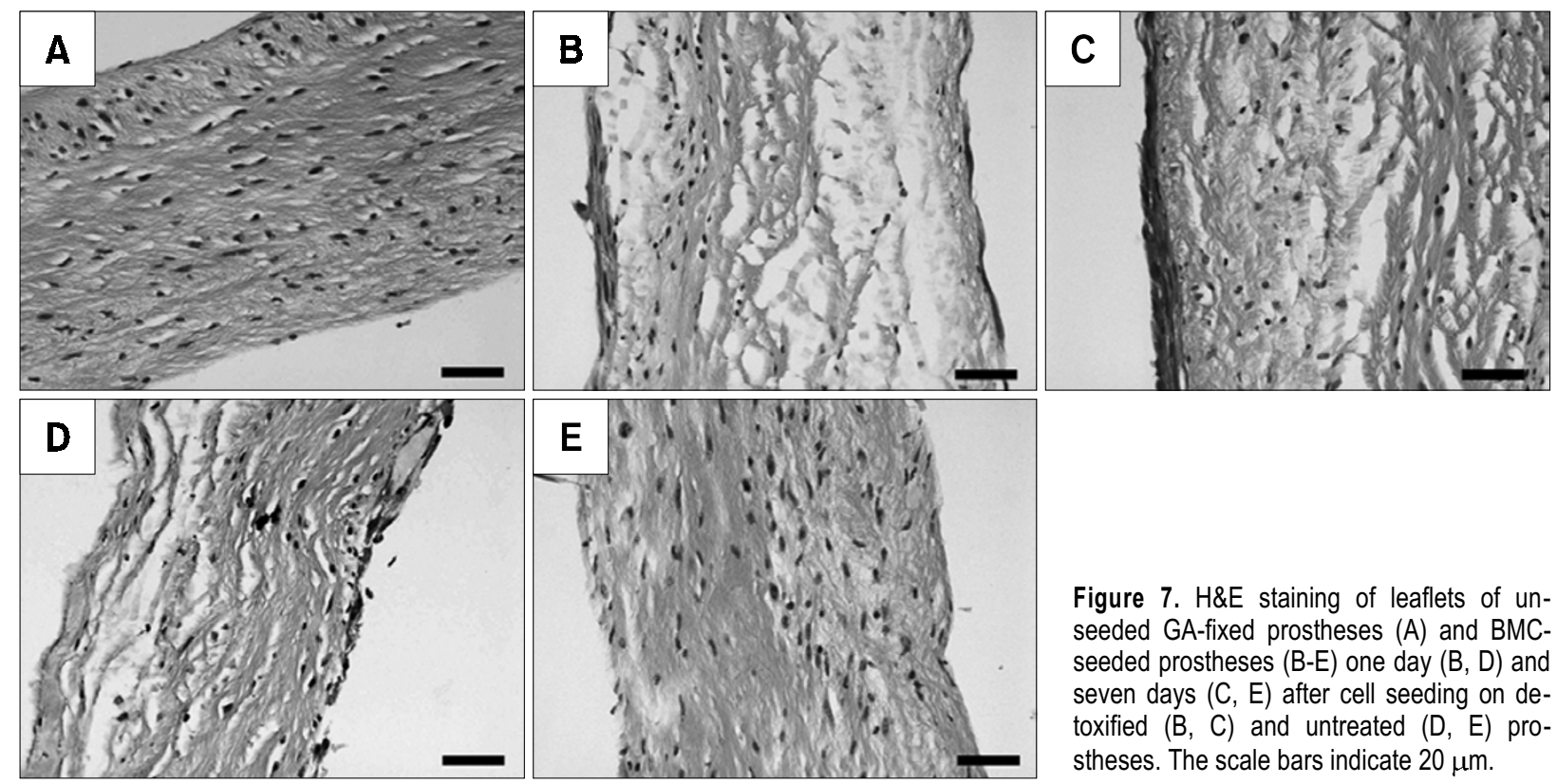

Figure 7. H\&E staining of leaflets of unseeded GA-fixed prostheses (A) and BMCseeded prostheses $(B-E)$ one day $(B, D)$ and seven days $(C, E)$ after cell seeding on detoxified $(B, C)$ and untreated $(D, E)$ prostheses. The scale bars indicate $20 \mu \mathrm{m}$.
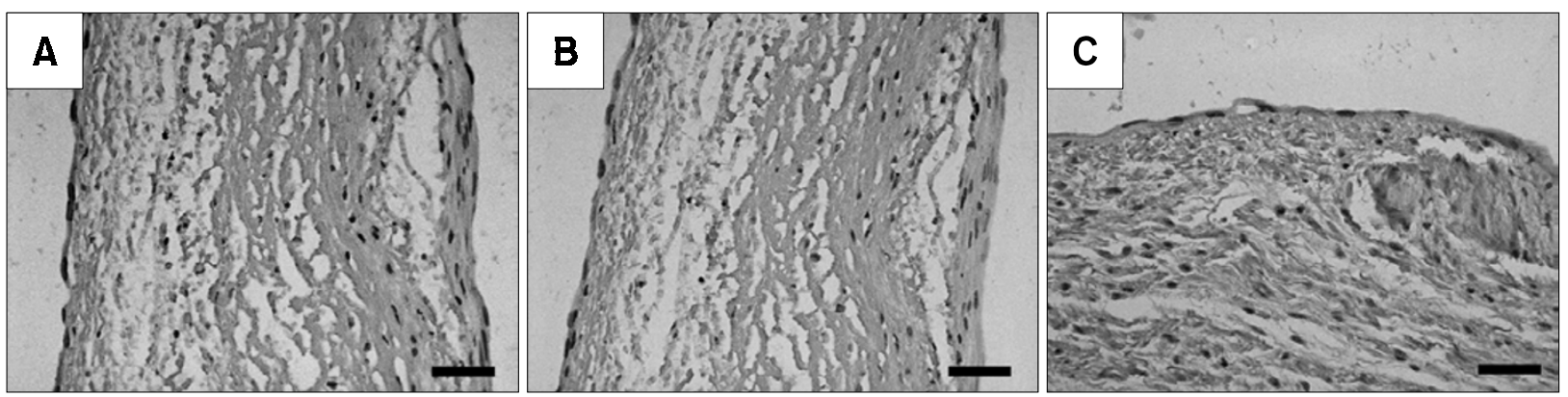

Figure 8. Immunohistochemical analysis of BMC-seeded detoxified prostheses seven days after cell seeding: (A) PCNA; (B) SM $\alpha$-actin; (C) CD31. The scale bars indicate $20 \mu \mathrm{m}$.

stained with EB (red) and only a few cells showed FDA-positive staining, indicating few viable cells on the surface (Figure $5 \mathrm{C}$ ). After seven days no viable cells were found on the untreated GA-fixed prostheses and all of the cells showed EB-positive staining (Figure 5D).

\section{MTT assay}

The MTT cytotoxicity assay showed the effect of the detoxifying treatment on the relative survival of BMCs on the GA-fixed valves, as measured by metabolic activity. BMCs cultured on detoxified prostheses showed a similar metabolic activity to those cultured on TCP, while BMCs cultured on untreated prostheses showed significantly reduced metabolic activity (Figure 6). These results verify the cytocompatibility of the detoxified GA-fixed prostheses. Cell survival and metabolic activity remain high on the detoxified GA-fixed prostheses for up to seven days after seeding.

\section{Histological and immunohistochemical analyses}

$H \& E$ staining of the valves one day after cell seeding showed that a high density of cells was present on the leaflets of the detoxified prostheses (Figure 7B), while only scattered BMCs were present on the leaflets of untreated prostheses (Figure 7D). Seven days after seeding, a stable and confluent cell layer was achieved on the detoxified prostheses (Figure $7 \mathrm{C}$ ), but no cells were observed on the surface of the leaflets of the untreated prostheses (Figure 7E).

The cells lining the leaflet surfaces of detoxified GA-fixed valves stained positively for PCNA, a marker of proliferating cells, at seven days after in vitro culture (Figure 8A). PCNA positive cells were only observed on the leaflet surfaces and not in the 
interstitial region. The cells on the leaflet surfaces also stained positively for SM $\alpha$-actin, a MF marker, (Figure $8 \mathrm{~B}$ ) and for CD31, an EC marker (Figure $8 C)$. However, positive staining for PCNA, CD31, and SM $\alpha$-actin was not observed on the surface of untreated GA-fixed prostheses at seven days after seeding.

\section{Discussion}

Successful engineering of heart valve tissue requires a safe and reliable scaffold. Although GAfixed valve prostheses have the disadvantage of cytotoxicity due to the fixation procedure, we used these prostheses as scaffolds for heart valve tissue engineering for the following reasons. The manufacturing process of these prostheses has been standardized; cross-linking by GA-fixation reduces immunogenicity; and the fixation process facilitates good mechanical properties and surgical handling (Gulbins et al., 2003). Therefore, these prostheses have several potential advantages as tissue engineering scaffolds which could be applied for clinical use in the future.

Several groups have studied seeding of human ECs on biological valve prostheses. However, seeding on GA-fixed valves has yielded poor results, mainly due to continual release of toxic GA and remaining free aldehyde groups (Fischlein et al., 1992; Hoffmann et al., 1992; Bengtsson et al., 1993; Fischlein and Fasol, 1996). In the present study, the initial seeding of BMCs on extensively rinsed untreated prostheses was successful, but the cells rapidly lost adhesion and did not survive seven days. The cytotoxicity of GA-fixed valves was significantly reduced by pre-incubation in cell culture medium and citric acid solution. During the GA-fixation process, GA covalently cross-links collagen fibers through the amino groups of the proteins, resulting in reduced immunogenicity and improved mechanical properties relative to fresh porcine aortic valves (Gulbins et al., 2003). After fixation, unbound GA can be washed out by rinsing with cell culture medium, but GA covalently bounded with collagen fibers can not simply be washed out, and the free aldehyde groups of this remaining GA causes cytotoxicity. The cross-linking of collagen fibers by GA-fixation also results in a hydrophobic surface, thus reducing the capability of cells to adhere, since cells attaching through pseudopodia that use non-covalent bonds require a hydrophilic surface (Gulbins et al., 2003). This hydrophobicity, combined with the toxicity of free aldehyde groups, results in poor adhesion and cell viability.

Our studies show that pretreatment with citric acid increased both cell adhesion and viability following seeding with BMCs. Citric acid reacts with free aldehyde groups, thus reducing cytotoxicity (Gulbins et al., 2003). In addition, citric acid is a strong organic acid that binds to amino groups of the collagen fibers, increasing the hydrophilicity of the surface and enhancing cellular attachment (Gulbins et al., 2003). Therefore, the detoxification treatment changed the surface properties of the prostheses to improve cellular adhesion.

Establishing a reliable cell source is also vital for the successful tissue engineering of heart valves. Various cell types have been used, including dermal fibroblasts (Shinoka et al., 1997), vascular-derived cells (Hoerstrup et al., 2000; Sodian et al., 2000), and mesenchymal stem cells from bone marrow (Hoerstrup et al., 2002; Kadner et al., 2002; Perry et al., 2003a; Perry and Roth, 2003b). However, dermal fibroblasts resulted in contracted and immobile leaflets (Shinoka et al., 1997). Vascular-derived cells are the most frequently used and have produced positive results in previous attempts to fabricate tissue engineered heart valves (Hoerstrup et al., 2000). However, this requires the sacrifice of intact tissues and additional invasive surgery to harvest cells. In addition, the characteristics of vascularderived cells are different from those of valvular cells, which may affect the function of tissue-engineered heart valves (Flanagan and Pandit, 2003).

BMCs are an attractive source of cells for the development of tissue-engineered heart valves that may overcome the limitations of other cell sources. Bone marrow aspiration is less invasive, and cell isolation is associated with much lower morbidity at the donor sites, than blood vessel biopsy (Kadner et al., 2002). Using patients' own BMCs, autologous valvular grafts could be constructed that may avoid immune rejection. Recently, a clinical case report demonstrated the feasibility of tissue engineering of human blood vessels with autologous bone marrow MNCs (Matsumura et al., 2003). In addition, cell therapy using autologous bone marrow MNCs or bone marrow AC133-positive cells has been clinically tested in humans for neovascularization in limb ischemia (Tateishi-Yuyama et al., 2002) or infarcted myocardium (Stamm et al., 2003). These results demonstrate the applicability of BMCs as an autologous cell source in the clinical treatment of cardiovascular diseases. We have previously reported the tissue engineering of small-diameter blood vessels and vascular smooth muscles using BMCs (Cho et al., 2004; 2005a; b), and several studies have used the bone marrow as a cell source for the tissue engineering of heart valves (Hoerstrup et al., 2002; Kadner et al., 2002; Perry et al., 2003a). In the present study, the potential of BMCs to differentiate 
into valvular cells has been shown, and the applicability of BMCs for the construction of tissueengineered heart valves was verified. We have identified culture conditions that allow for the proliferation and differentiation of the multiple cell types necessary for valvular tissue regeneration. Genetic and immunochemical characterization demonstrated that cultured BMCs could differentiate into EC-like cells and MF-like cells by exposure to the appropriate culture conditions.

In summary, this study demonstrated the tissue engineering of biological valvular prostheses in vitro using detoxified GA-fixed prostheses and BMCs. The heart valves engineered with valvular cells induced from BMCs showed tissue regeneration with a CD31-positive layer. Before such recellularized valves can be used in clinical procedures, in vivo experiments are necessary to prove whether the seeded BMC layer improves biocompatibility and durability of the GA-fixed valve prostheses. Because physical stress on the valvular structures plays an important role in bioprosthetic degeneration, a large animal model such as an ovine model should be used to test the valves under physiological conditions. In addition, the method of cell seeding on prostheses needs to be further improved. Although the detoxified prostheses demonstrate improved biocompatibility, the initial cell adhesion ratio is low. This may be due to the immediate detachment of BMCs from the leaflets after cell seeding. It is possible that cell seeding and in vitro maintenance in a static culture condition is inefficient, and that dynamic cell seeding (Kim et al., 1998) and preconditioning of the seeded prostheses in a pulsatile bioreactor might improve cell adhesion ratio and tissue regeneration. Further characterization of valvular cells differentiated from bone marrow MNCs is also necessary, and additional studies related to the growth, remodeling, durability, calcification and function of tissue-engineered heart valves with respect to long-term implantation are required.

\section{Acknowledgment}

This work was supported by a grant of the Korea Health 21 R\&D Project, Ministry of Health and Welfare, Republic of Korea (Grant No. 01-PJ1-PG101CH11-0003).

\section{References}

Bengtsson L, Radegran K, Haegerstrand A. In vitro endothelialization of commercially available heart valve bioprostheses with cultured adult human cells. Eur J Cardiothorac Surg 1993;7:393-8

Cho SW, Kim IK, Lim SH, Kim DI, Kang SW, Kim SH, Kim YH,
Lee EY, Choi CY, Kim BS. Smooth muscle-like tissues engineered with bone marrow stromal cells. Biomaterials 2004;25:2979-86

Cho SW, Lim SH, Kim IK, Hong YS, Kim SS, Yoo KJ, Park HY, Jang Y, Chang BC, Choi CY, Hwang KC, Kim BS. Small-diameter blood vessels engineered with bone marrow-derived cells. Ann Surg 2005a;241:506-15

Cho SW, Park HJ, Ryu JH, Kim SH, Kim YH, Choi CY, Lee MJ, Kim JS, Jang IS, Kim DI, Kim BS. Vascular patches tissue-engineered with autologous bone marrow-derived cells and decellularized tissue matrices. Biomaterials 2005b;26:1915-24

Choi SC, Yoon J, Shim WJ, RO YM, Lim DS. 5-azacytidine induces cardiac differentiation of P19 embryonic stem cells. Exp Mol Med 2004;36:515-23

Fischlein T, Fasol R. In vitro endothelialization of bioprosthetic heart valves. J Heart Valve Dis 1996;5:58-65

Fischlein T, Lehner G, Lante W, Reichart B. Endothelialization of aldehyde-fixed cardiac valve bioprostheses. Transplant Proc 1992;24:2988

Fischlein T, Lehner G, Lante W, Fittkau M, Murphy JG, Weinhold C, Reichart B. Endothelialization of cardiac valve bioprostheses. Int J Artif Organs 1994;17:345-52

Flanagan TC, Pandit A. Living artificial heart valve alternatives: a review. Eur Cell Mater 2003;6:28-45

Gulbins H, Goldemund A, Anderson I, Haas U, Uhlig A, Meiser $B$, Reichart B. Preseeding with autologous fibroblasts improves endothelialization of glutaraldehyde-fixed porcine aortic valves. J Thorac Cardiovasc Surg 2003;125:592-601

Hoerstrup SP, Sodian R, Daebritz S, Wang J, Bacha EA, Martin DP, Moran AM, Guleserian KJ, Sperling JS, Kaushal S, Vacanti JP, Schoen FJ, Mayer JE Jr. Functional living trileaflet heart valves grown in vitro. Circulation 2000;102:III44-9

Hoerstrup SP, Kadner A, Melnitchouk S, Trojan A, Eid K, Tracy J, Sodian R, Visjager JF, Kolb SA, Grunenfelder J, Zund G, Turina MI. Tissue engineering of functional trileaflet heart valves from human marrow stromal cells. Circulation 2002; 106:1143-50

Hoffman D, Gong G, Liao K, Macaluso F, Nikolic SD, Frater RW. Spontaneous host endothelial growth on bioprostheses. Influence of fixation. Circulation 1992;86:II75-9

Ishida A, Wu MH, Shi Q, Fujita Y, Sauvage LR, Hammond WP, Wijelath ES. Dynamic changes of smooth muscle and endothelial markers in the early healing process of dacron vascular grafts in the dog, using RT-PCR. Int J Angiol 2000;9:107-10

Kadner A, Hoerstrup SP, Zund G, Eid K, Maurus C, Melnitchouk S, Grunenfelder J, Turina MI. A new source for cardiovascular tissue engineering: human bone marrow stromal cells. Eur J Cardiothorac Surg 2002;21:1055-60

Kalra M, Jost CJ, Severson SR, Miller VM. Adventitial versus intimal liposome-mediated ex vivo transfection of canine saphenous vein grafts with endothelial nitric oxide synthase gene. J Vasc Surg 2000;32:1190-200

Kim BS, Putnam AJ, Kulik TJ, Mooney DJ. Optimizing seeding and culture methods to engineer smooth muscle tissue on biodegradable polymer matrices. Biotechnol Bioeng 1998;57: 
$46-54$

Liu ML, Hong ST, Early phase of amyloid $\beta 42$-induced cytotoxicity in neuronal cells is associated with vacuole formation and enhancement of exocytosis. Exp Mol Med 2005;37:559-66

Lupinetti FM, Warner J, Jones TK, Herndon SP. Comparison of human tissues and mechanical prostheses for aortic valve replacement in children. Circulation 1997;96:321-5

Matsumura G, Hibino N, Ikada Y, Kurosawa H, Shin'oka T. Successful application of tissue engineered vascular autografts: clinical experience. Biomaterials 2003;24:2303-8

Moritz A, Grimm M, Eybl E, Grabenwoger M, Windberger U, Dock W, Bock $P$, Wolner E. Improved biocompatibility by postfixation treatment of aldehyde fixed bovine pericardium. ASAIO Trans 1990;36:M300-3

Murata M, Kador PF, Sato S. Vascular endothelial growth factor (VEGF) enhances the expression of receptors and activates mitogen-activated protein (MAP) kinase of dog retinal capillary endothelial cells. J Ocul Pharmacol Ther 2000;16: 383-91

Perry TE, Kaushal S, Sutherland FW, Guleserian KJ, Bischoff J, Sacks M, Mayer JE. Thoracic Surgery Directors Association Award. Bone marrow as a cell source for tissue engineering heart valves. Ann Thorac Surg 2003a;75:761-7

Perry TE, Roth SJ. Cardiovascular tissue engineering: constructing living tissue cardiac valves and blood vessels using bone marrow, umbilical cord blood, and peripheral blood cells. J Cardiovasc Nurs 2003b;18:30-7

Ryu JH, Kim SS, Cho SW, Choi CY, Kim BS. HEK 293 cell suspension culture using fibronectin-adsorbed polymer nanospheres in serum-free medium. J Biomed Mater Res A 2004;71:128-33

Shinoka T, Shum-Tim D, Ma PX, Tanel RE, Langer R, Vacanti JP, Mayer JE Jr. Tissue-engineered heart valve leaflets: does cell origin affect outcome? Circulation 1997;96:II-102-7

Sodian R, Hoerstrup SP, Sperling JS, Daebritz S, Martin DP, Moran AM, Kim BS, Schoen FJ, Vacanti JP, Mayer JE Jr. Early in vivo experience with tissue-engineered trileaflet heart valves. Circulation 2000;102:III22-9

Stamm C, Westphal B, Kleine HD, Petzsch M, Kittner C, Klinge H, Schumichen C, Nienaber CA, Freund M, Steinhoff G. Autologous bone-marrow stem-cell transplantation for myocardial regeneration. Lancet 2003;361:45-6

Tateishi-Yuyama $\mathrm{E}$, Matsubara $\mathrm{H}$, Murohara $\mathrm{T}$, Ikeda $\mathrm{U}$, Shintani S, Masaki H, Amano K, Kishimoto Y, Yoshimoto K, Akashi $\mathrm{H}$, Shimada K, Iwasaka T, Imaizumi T. Therapeutic Angiogenesis using Cell Transplantation (TACT) Study Investigators. Therapeutic angiogenesis for patients with limb ischaemia by autologous transplantation of bone-marrow cells: a pilot study and a randomised controlled trial. Lancet 2002;360:427-35

Trantina-Yates AE, Human P, Bracher M, Zilla P. Mitigation of bioprosthetic heart valve degeneration through biocompatibility: in vitro versus spontaneous endothelialization. Biomaterials 2001;22:1837-46

Weissenstein C, Human P, Bezuidenhout D, Zilla P. Glutaraldehyde detoxification in addition to enhanced amine crosslinking dramatically reduces bioprosthetic tissue calcification in the rat model. J Heart Valve Dis 2000;9:230-40

Yacoub M, Rasmi NR, Sundt TM, Lund O, Boyland E, Radley-Smith R, Khaghani A, Mitchell A. Fourteen-year experience with homovital homografts for aortic valve replacement. J Thorac Cardiovasc Surg 1995; 110:186-93

Zilla P, Fullard L, Trescony P, Meinhart J, Bezuidenhout D, Gorlitzer M, Human P, von Oppell U. Glutaraldehyde detoxification of aortic wall tissue: a promising perspective for emerging bioprosthetic valve concepts. J Heart Valve Dis 1997;6:510-20 